\title{
Rancang Bangun Robot Pemindah Barang Berbasis Mikrokontroler Untuk Monitoring Stok Gudang
}

\author{
Bima Jodhi Satria ${ }^{1}$, Sumaryanto ${ }^{2}$ \\ ${ }^{1}$ Program Studi Sistem Komputer Sekolah Tinggi Elektronika dan Komputer Semarang \\ Jl. Majapahit 605 Semarang, telp : (024)-6723456, e-mail: bimajodhie@gmail.com \\ ${ }^{2}$ Program Studi Sistem Komputer Sekolah Tinggi Elektronika dan Komputer Semarang \\ Jl. Majapahit 605 Semarang, telp : (024)-6723456, e-mail: smryt2day359@gmail.com
}

ARTICLE INFO

Article history:

Received 30 Mei 2020

Received in revised form 2 Juni 2020

Accepted 10 Juni 2020

Available online 24 Juli 2020

\section{ABSTRACT}

This study generally aims to design an information system that can handle problems in putting and sorting goods into warehouses at $\mathrm{CV}$. Sekar Intan KIC Gatsu, Semarang. In terms of using the Information System, CV. Sekar Intan KIC Gatsu, Semarang. In the transfer and sort of goods in the warehouse still using a manual system when the implementation, warehouse employees must take and place the goods to the warehouse that has been determined each - each type of item, so employees must calculate the number of items when the goods take place, here various problems occur, because it requires some HR to manage the warehouse performance process at CV. Sekar Intan.

To support the research, researchers used Research and Development (R \& D) research methods through the microcontroller-based moving robot design simulation design stages that have been tested by experts declared valid with Valid validity levels and final product development design simulation prototypes carried out. goods transfer robot uses Arduino IDE development software that is integrated with Arduino Mega 2560, 6 pin line sensor, dc motor, motor driver, servo motor, motor driver, lcd, and has been tested in the field by General Adv. Administration and HRD as users / users and stated to be very effective.

Based on the results of the research and discussion, it can be concluded that the robot design system developed can overcome the problems in the old system on the CV. Sekar Intan KIC Gatsu Semarang, so as to produce a system that can facilitate work processes and parking processes for employees to be more effective and efficient. 
Keywords: Arduino IDE integrated with Arduino

Mega 2560, 6 pin line sensor, dc motor, motor

driver, servo motor, motor driver, lcd.

\section{Pendahuluan}

Perkembangan teknologi yang semakin pesat pada zaman modern ini mendorong manusia untuk terus berinovasi dalam menciptakan sarana dan prasarana, serta membuat hal-hal yang diluar nalar menjadi nyata dan berguna. Dengan mengetahui mekanik sebuah robotika dan sistem pemrograman, banyak hal-hal yang sederhana sampai sulit sekalipun dapat dipelajari dan berinovasi untuk menciptakan sebuah karya yang berguna untuk masyarakat dan perusahaan, seperti halnya rancang bangun robot pemindah barang berbasis mikrokontroler untuk monitoring stok gudang.

CV. Sekar Intan ini adalah perusahaan yang bergerak di bidang penjualan alat teknik, dimana perusahaan tersebut memiliki beberapa ruang penyimpanan yang disebut gudang untuk menyimpan barang yang turun dari supplier. Di perusahaan tersebut memiliki sebuah fasilitas tiga ruang penyimpanan barang yang setiap gudangnya memiliki aturan jenis barang di setiap gudang masing - masing, jenis - jenis barang ini meliputi bahan perairan, konstruksi pabrik, dan peralatan tukang. Didalam proses kinerja gudang terjadi banyak kendala dan faktor yang menunjang kegagalan dalam pemindahan barang kegudang. Karyawan gudang membutuhkan waktu cukup banyak dalam pemindahan barang kegudang karena karyawan gudang harus memindahkan barang tersebut ke setiap gudang masing - masing yang sudah ditentukan aturan jenis - jenis barang. Muatan barang juga menjadi kendala dalam proses pemindahan barang kegudang terkadang berat barang bisa mencapai satu ton bahkan lebih dan di situ perlu adanya penambahan sumber daya manusia untuk mengangkat barang tersebut ke gudang yang sudah ditentukan. Begitu banyaknya barang yang turun dengan banyaknya jenis barang, karyawan gudang sering melakukan kesalahan dalam penempatan kegudang masing - masing. Kecelakan fisik dapat terjadi karena adanya bahan barang yang mungkin membahayakan tubuh yang bersangkutan saat proses pemindahan barang dilakukan. Setelah barang masuk kegudang karyawan gudang harus menghitung secara manual di setiap gudang masing - masing setelah barang turun. Proses dalam menghitung satu persatu memang membutuhkan dalam merekap barang, karena sering terjadi kesalahan dalam menghitung jumlah barang yang berbeda dalam penempatannya ke setiap gudang. Saat ini pimpinan menginginkan adanya perangkat agar dapat di monitoring dan karyawan juga menginginkan demikian untuk dapat memonitoring jumlah barang yang masuk kegudang.

Arduino adalah kit elektronik atau papan elektronik open source yang didalamnya terdapat komponen utama, yaitu sebuah chip mikrokontroler dengan jenis AVR dari perusahaan Atmel. Mikrokontroller itu sendiri adalah chip atau IC ( Integrated Circuit ) yang bisa di program menggunakan komputer. Tujuan menanamkan program pada mikrokontroler adalah agar rangkaian elektronik dapat membawa input, memproses input tersebut dan kemudian menghasilkan output sesuai dengan keinginan. Jadi Mikrokontroler bertugas sebagai otak yang mengendalikan input, proses dan output sebuah rangkaian elektronik. Arduino memiliki banyak macam jenis, salah satunya adalah yang dipakai oleh penulis yaitu Arduino Mega 2560.

Pengertian dari arduino Mega 2560 merupakan papan pengembangan mikrokontroller yang berbasis Arduino dengan menggunakan chip ATmega2560. Board ini memiliki pin I/O yang cukup banyak, sejumlah 54 buah digital I/O pin (15 pin diantaranya adalah PWM), 16 pin analog input, 4 pin UART (serial port hardware). Arduino Mega 2560 dilengkapi dengan sebuah oscillator $16 \mathrm{Mhz}$, sebuah port USB, power jack DC, ICSP header, dan tombol reset. Board ini sudah sangat lengkap, sudah memiliki segala sesuatu yang dibuthkan untuk sebuah mikrokontroller. Dengan penggunaan yang cukup sederhana, tinggal menghubungkan power dari USB ke PC atau melalui adaptor AC/DC ke jack DC.

Rancang Bangun Robot Pemindah Barang Berbasis Mikrokontroler Untuk Monitoring Stok Gudang 
Dengan Robot Pemindah Barang bersifat robotik sehingga barang bisa dipindahkan dengan cepat dan terstruktur ke setiap gudang masing-masing. Karyawan gudang cukup menanti data barang yang ditampilkan robot di LCD $16 \times 2$ untuk mengetahui barang yang masuk ke dalam gudang menggunakan robot dengan bantuan sensor warna. Data barang tersebut akan diproses di dalam robot tersebut yang tersimpan di Arduino Mega 2560, ditampilkan pada LCD robot. Data barang tersimpan didalam sistem yang aman sehingga jarang terjadi kerusakan dan hilang. Tidak ada biaya buku dan alat tulis sehingga menghemat pengeluaran, yang terpenting adalah jenis setiap barang yang berbeda akan dipindahkan dan mengetahui jumlah stok gudang oleh robot dengan ketentuan yang diinginkan perusahaan ke setiap gudang masing-masing. Dengan demikian gudang akan mengalami keberhasilan yang tersistematis didalam menyusun dan mengetahui data barang secara cepat dan akurat.

\section{Metode Penelitian}

Pada penelitian ini, metode pengembangan yang digunakan adalah metode penelitian dan pengembangan atau yang biasa disebut R\&D (Research and Development). Borg and Gall mengemukakan langkah - langkah dalam penelitian dan pengembangan yang bersifat siklus seperti yang terlihat pada tabel berikut :

Berikut penjelasan langkah - langkah penelitian dan pengembangan menurut Borg and Gall :

1. Research and Information Collecting, termasuk dalam langkah ini antara lain studi literatur yang berkaitan dengan permasalahan yang dikaji dan persiapan untuk merumuskan kerangka kerja penelitian.

2. Planning, termasuk dalam langkah ini merumuskan kecakapan dan keahlian yang berkaitan dengan permasalahan, menentukan tujuan yang akan dicapai pada setiap tahapan, dan jika mungkin atau diperlukan melaksanakan studi kelayakan secara terbatas, memikirkan produk apa yang akan dihasilkan

3. Develop preliminary form of produk, yaitu mengembangkan bentuk permulaan dari produk yang akan dihasilkan. Produk bisa berupa algoritma, desain program, model program. Termasuk dalam langkah ini adalah persiapan komponen pendukung, menyiapkan pedoman dan buku penunjuk dan melakukan evaluasi terhadap kelayakan alat - alat pendukung produk rancangan ini bila perlu dilakukan validasi yang menguasai permasalahan yang diprogramkan.

4. Preliminary field testing, yaitu melakukan uji coba lapangan awal dalam skala terbatas yang melibatkan subjek secukupnya yang menguasai permasalahan yang diprogramkan. Pada langkah ini pengumpulan dan analisis data dapat dilakukan dengan cara wawancara, observasi atau angket untuk melakukan cross check yang dirancang dengan aplikasi sudah memenuhi atau belum.

5. Main product revision, yaitu melakukan perbaikan terhadap produk awal yang dihasilkan berdasarkan hasil uji coba awal. Perbaikan ini sangat mungkin dilakukan lebih dari satu kali, sesuai dengan hasil yang ditunjukan dalam uji coba terbatas, sehingga diperoleh draft produk (model) utama yang siap diujikan lebih luas.

6. Main field testing, uji coba yang melibatkan stage holder, disini dapat diuji coba output running program dengan mendapatkan pengesahan dari pihak ruang lingkup penelitian.

\section{Hasil dan Pembahasan}

JURNAL ILMIAH ELEKTRONIKA DAN KOMPUTER Vol. 13, No. 1, Juli $2020: 68-77$ 
71

JURNAL ILMIAH ELEKTRONIKA DAN KOMPUTERp-ISSN: $1907-0012$ e-ISSN : 2714-5417.

\subsection{Use Case Diagram}

Dibawah ini adalah use case diagram langkah dan sistem kerja sensor dengan aktor karyawan gudang dan berbagai use case terbentuk didalam robot pemindah barang ke gudang yang meliputi sensor - sensor yang terbangun untuk proses kinerja gudang.

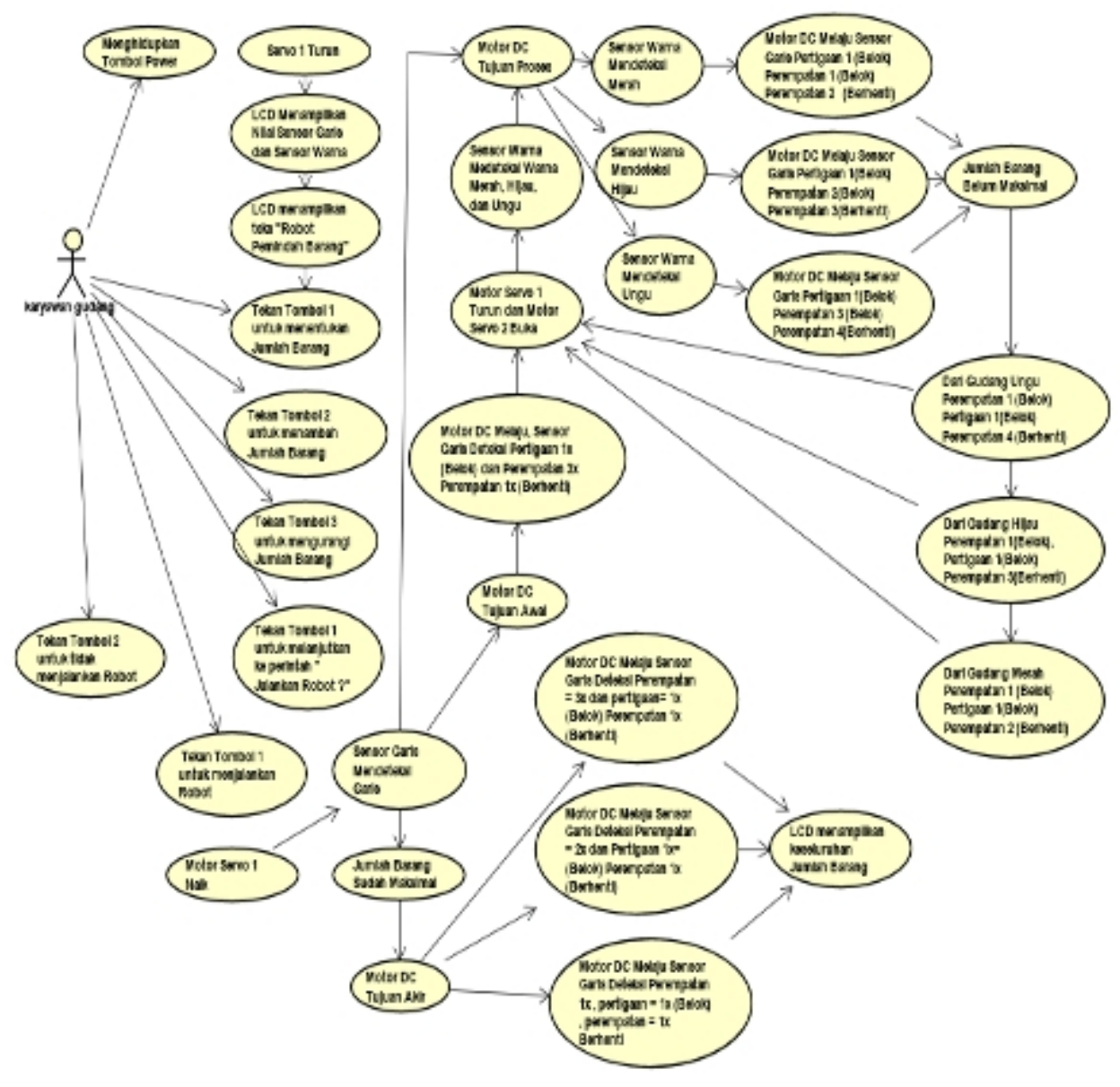

Rancang Bangun Robot Pemindah Barang Berbasis Mikrokontroler Untuk Monitoring Stok Gudang 


\subsection{Tampilan Keseluruhan Robot Pemindah Barang}

Di bawah ini adalah tampilan keseluruhan robot pemindah barang, dengan menggunakan pondasi pcb tersusun kombinasi sensor - sensor dan motor sehingga membentuk struktur bangun robot pemindah barang seperti dibawah ini.

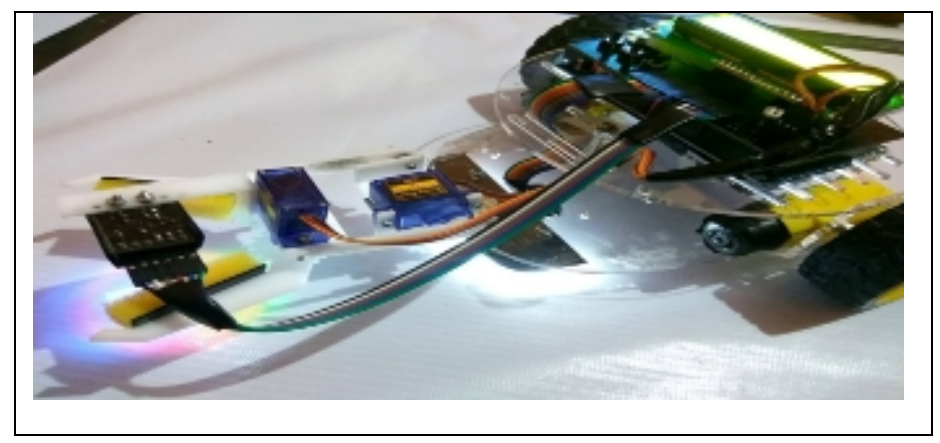

Gambar 1

Tampilan Keseluruhan Robot Pemindah Barang

\subsection{Tampilan LCD Merekap Nilai Garis}

Di bawah ini adalah proses dimana sesor garis membaca dan merekam garis yang sudah ditentukan dan ditampilkan di lcd, karena adanya 6 titik sensor garis untuk memulai dan mengakiri jalannya motor dc.
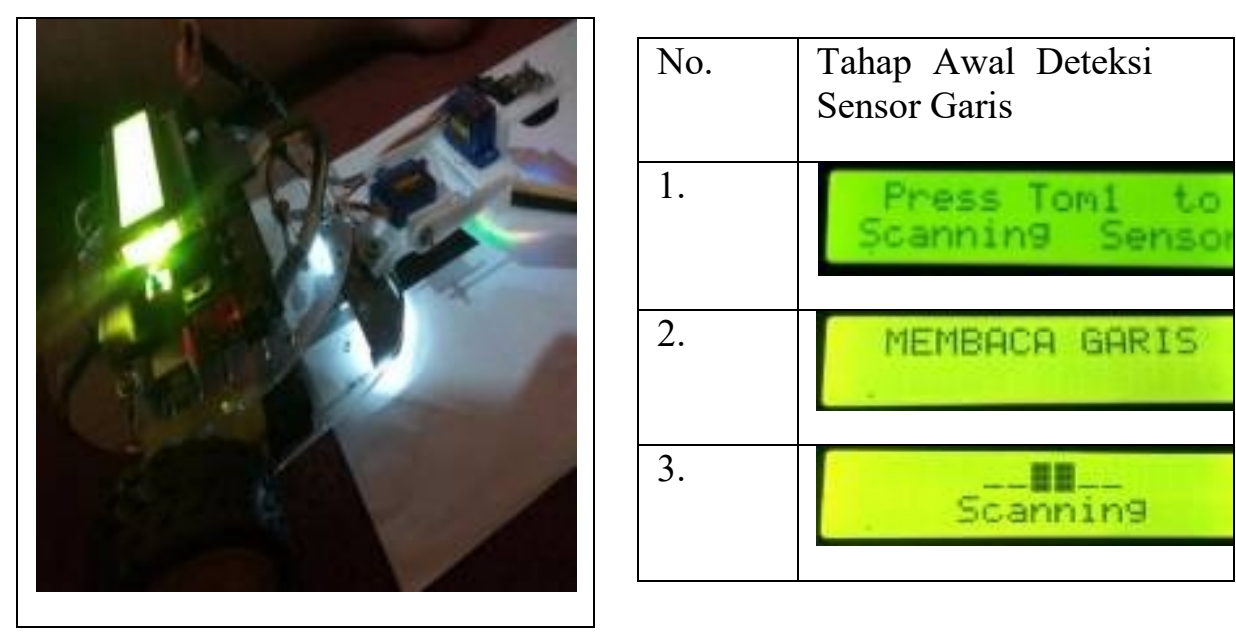

Gambar 2

Tampilan LCD Rekap Nilai Garis

JURNAL ILMIAH ELEKTRONIKA DAN KOMPUTER Vol. 13, No. 1, Juli $2020: 68-77$ 


\subsection{Tampilan LCD Merekap Warna Ungu}

Di bawah ini adalah proses merekap nilai warna ungu yang terdapat pada barang tersebut. Dengan menggunakan sensor warna dan nilai warnanya ditampilkan di lcd.
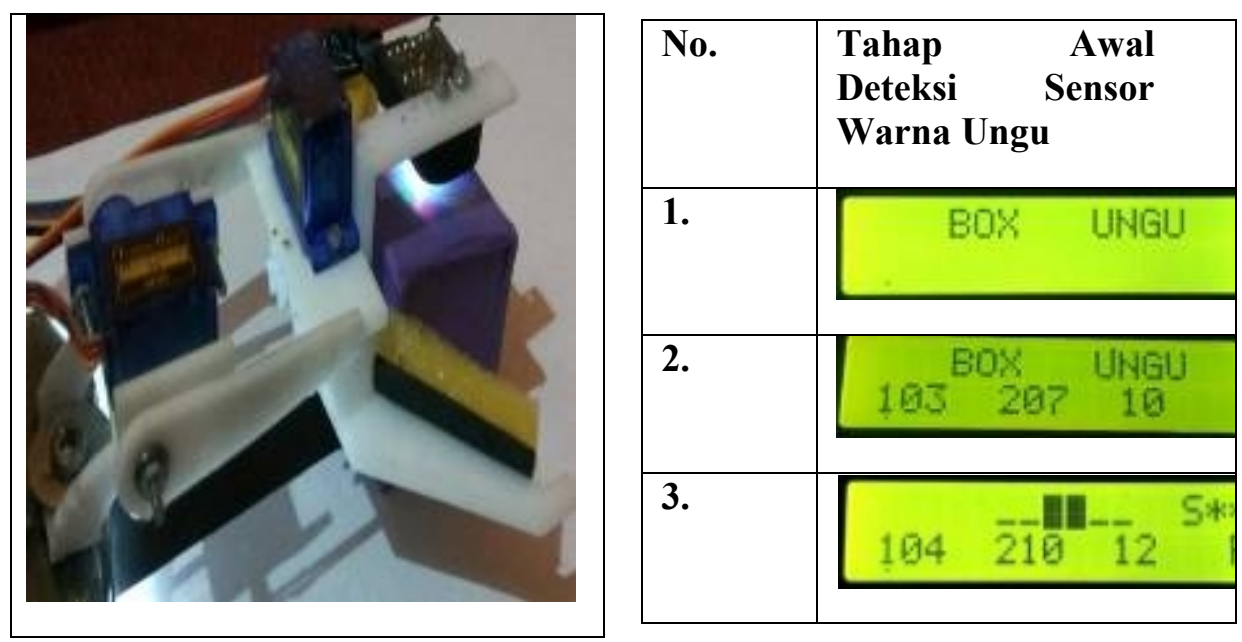

\section{Gambar 3}

Tampilan LCD Rekap Nilai Warna Ungu

\subsection{Tampilan LCD Merekap Warna Merah}

Di bawah ini adalah proses merekap nilai warna merah yang terdapat pada barang tersebut. Dengan menggunakan sensor warna dan nilai warnanya ditampilkan di lcd.
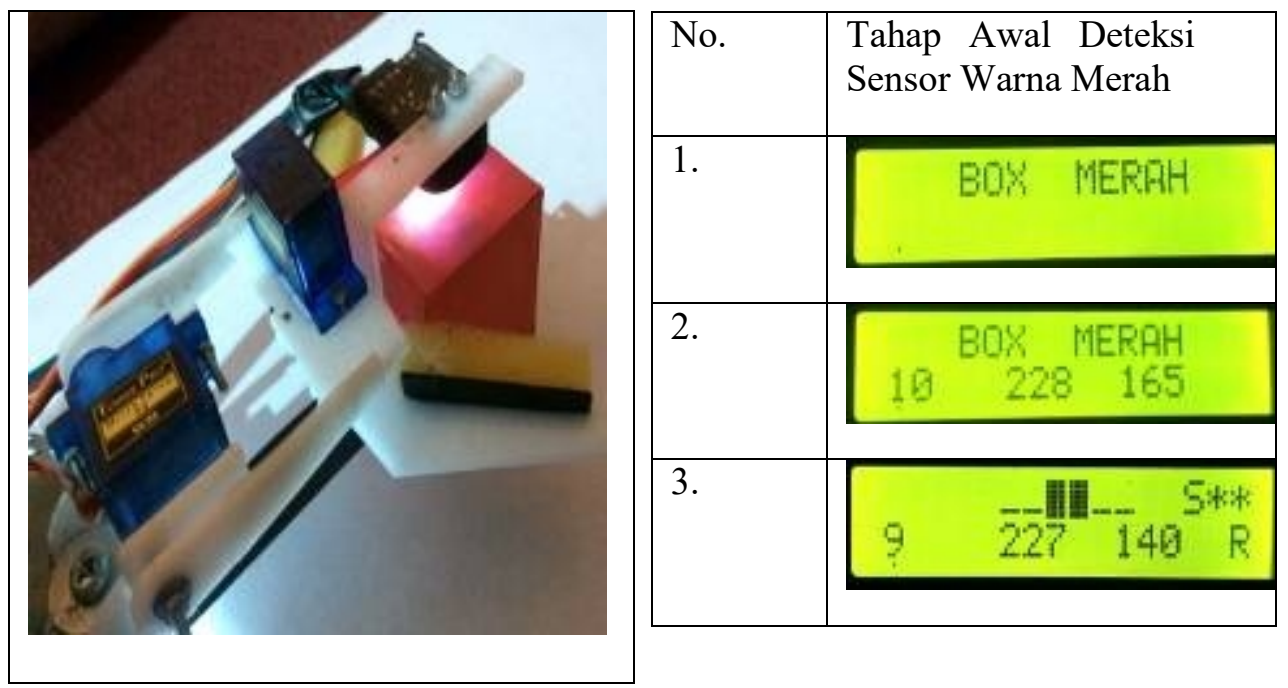

Gambar 4.

Tampilan LCD Rekap Nilai Warna Merah

Rancang Bangun Robot Pemindah Barang Berbasis Mikrokontroler Untuk Monitoring Stok Gudang 


\subsection{Tampilan LCD Merekap Warna Hijau}

Di bawah ini adalah proses merekap nilai warna merah yang terdapat pada barang tersebut. Dengan menggunakan sensor warna dan nilai warnanya ditampilkan di lcd.
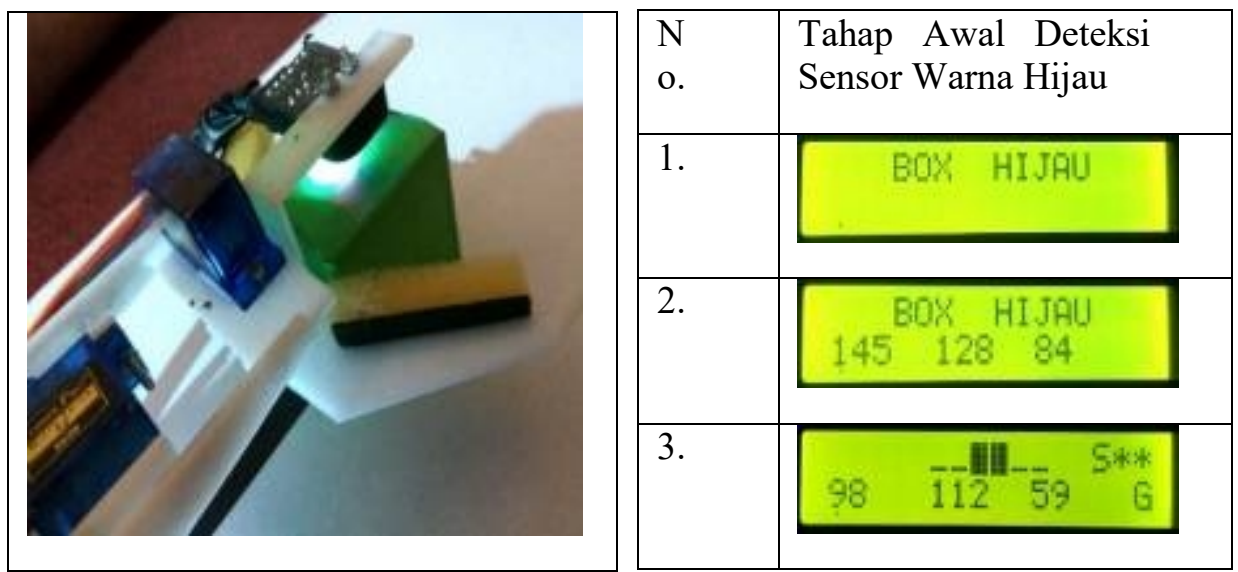

\section{Gambar 5}

Tampilan Prototipe dan LCD Rekap Nilai Warna Hijau

\subsection{Tampilan LCD Menentukan Jumlah Barang}

Di bawah ini adalah proses pertama untuk menjalankan robot pemindah barang dengan menentukan jumlah barang menggunakan tombol yang berada pada modul kombinasi. Perintah tersebut ditampilan di led dengan tampilan seperti dibawah ini :
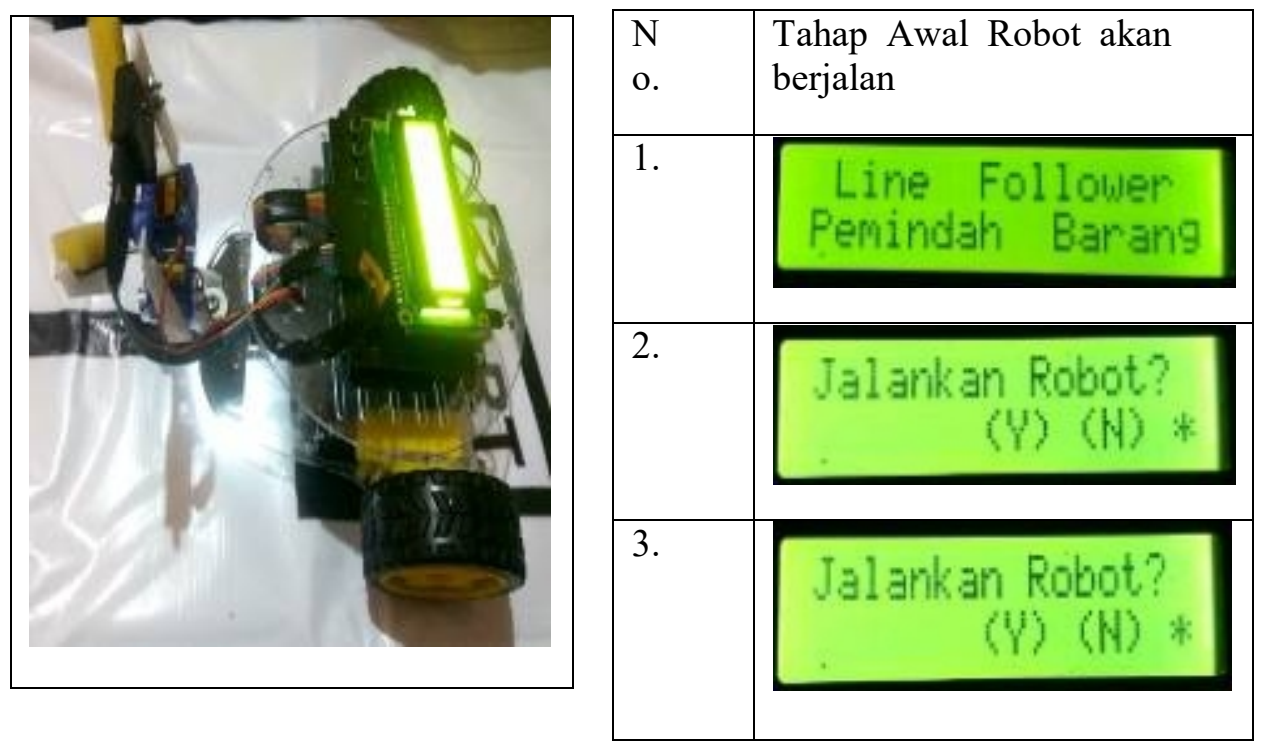

Gambar 6

Tampilan LCD Menentukan Jumlah Barang.

JURNAL ILMIAH ELEKTRONIKA DAN KOMPUTER Vol. 13, No. 1, Juli $2020: 68-77$ 


\subsection{Tampilan LCD Mengambil Barang}

Di bawah ini adalah proses kedua barang pemindah barang untuk mengambil barang ke tempat pengambilan barang, dengan mendeteksi warna yang dilakukan oleh sensor warna, berikut tampilan gambar dibawah ini :

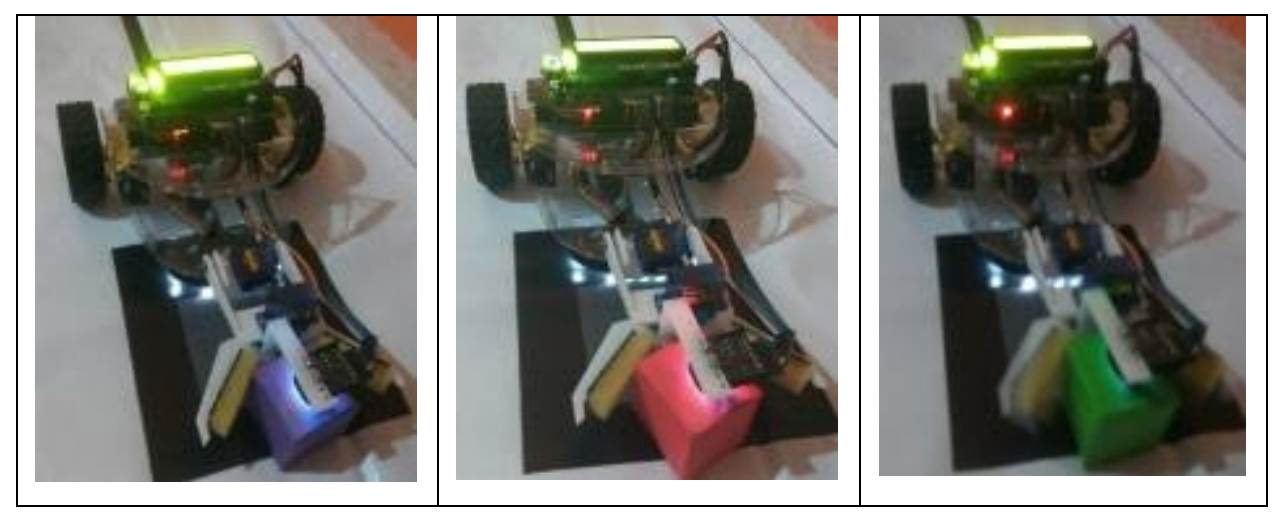

\section{Gambar 7}

Tampilan Saat Mengambil Barang.

\subsection{Tampilan Saat Meletakkan Barang}

Di bawah ini adalah tampilan robot pemindah barang saat proses pengambilan barang ke tujuan serta mendeteksi warna barang dengan sensor warna yang akan di ambil dan di letakkan pada gudang yang sudah ditentukan setiap warnanya.

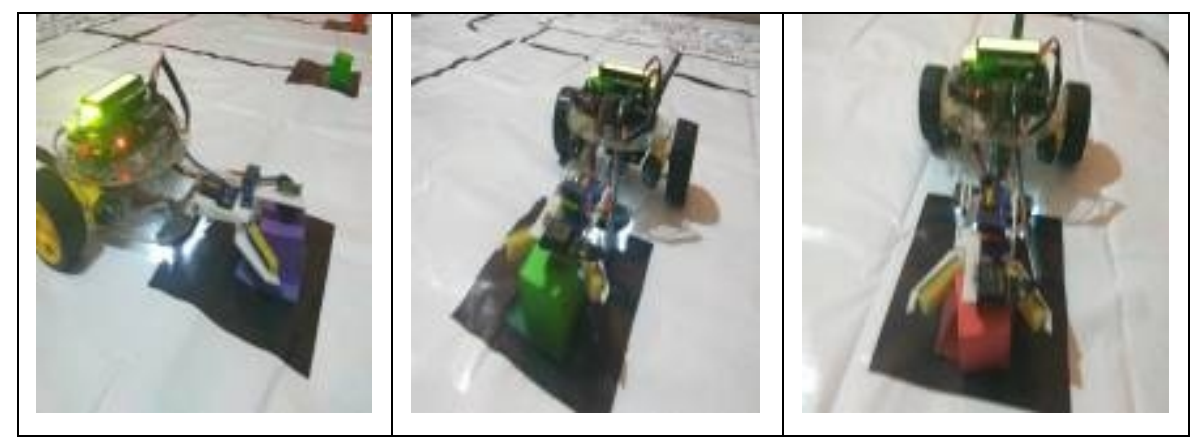

\section{Gambar 8}

Tampilan Saat Meletakkan Barang.

\subsection{Tampilan LCD Hasil Akir}

Di bawah ini adalah tampilan robot pemindah barang saat proses telah selesai dalam meletakkan barang ke gudang yang sudah ditentukan setiap warnanya dan lcd menampilkan hasil dari setiap gudang dan total barangnya.

Rancang Bangun Robot Pemindah Barang Berbasis Mikrokontroler Untuk Monitoring Stok Gudang 


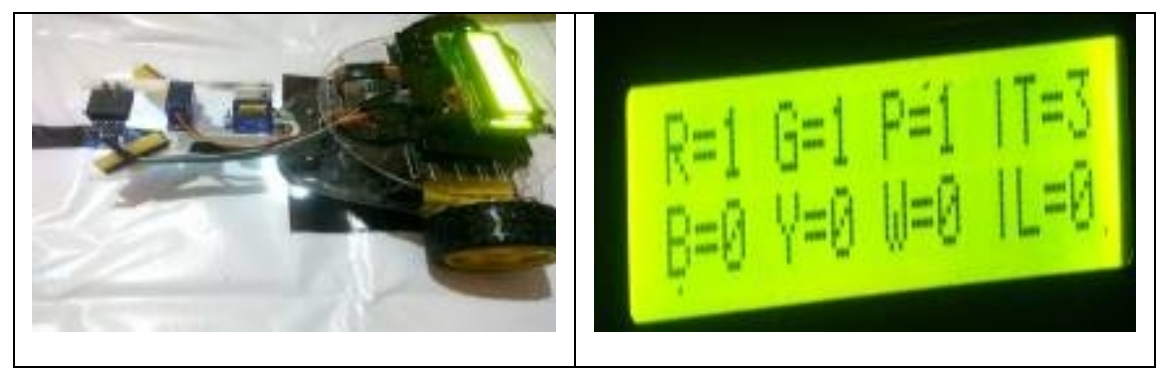

Gambar 9

Tampilan Akhir LCD.

\section{Kesimpulan}

Berdasarkan hasil analisis data pada pengembangan produk sistem informasi gudang yang di lakukan di CV. Sekar Intan. Dengan metode Research and Development (R\&D), bahwa kerja sistem lama yang menggunakan tenaga sumber daya manusia untuk memindahkan barang, perhitungan jumlah barang, dan sortir barang ke setiap gudang yang sudah tentukan secara manual ini dirasa kurang efisien dan efektif karena hal ini memerlukan banyak waktu, tenaga, dan kesalahan sortir saat proses pemindahan barang ke gudang masing - masing.

Setelah dibangun sistem baru yang telah melalui pengujian desain oleh pakar dan juga uji coba prototype oleh user, rancang bangun robot pemindah barang yang telah dikembangkan dinyatakan layak untuk dikembangkan lebih lanjut, dan dapat ditarik kesimpulan :

a) Rancang Bangun Robot Pemindah Barang Berbasis Mikrokontroler Untuk Monitoring Stok Gudang secara umum telah berhasil bekerja sesuai dengan rancangan seperti menentukan jumlah barang, pengambilan barang, meletakkan barang dan hasil akir tampilan lcd.

b) Pada kondisi ideal, sensor warna dapat membaca dengan baik warna barang dengan jarak yang sudah terekam oleh sensor warna ungu, warna merah, warna hijau.

c) Lebih mudah didalam penyortiran jenis barang ke gudang masing - masing yang sudah ditentukan.

d) Didalam merekap jumlah dan jenis barang dipermudahkan karena hasil tersebut setelah selesai melakukan pemindahan barang, data akan tampil di layar lcd robot yang ditunjukan.

\section{DAFTAR PUSTAKA}

[1] Mardi. 2014. "Sistem Informasi Akuntansi Bogor": Ghalia Indonesia.

[2] Hanif Al Fatta. 2007. "Analisis dan Perancangan Sistem Informasi”Jakarta: Andi Publisher

JURNAL ILMIAH ELEKTRONIKA DAN KOMPUTER Vol. 13, No. 1, Juli $2020: 68-77$ 
[3] Arel, Riedsa.2018. "Analisis dan Perancangan Sistem Informasi Manajemen Gudang pada PT Mitra Pinasthika Mulia", Surabaya: JPTIIK

[4] Artanto, Dian. 2012. "Yuk Membuat Robot". Jakarta : Gramedia Widiasarana Indonesia.

[5] Ifran. 2014. "Sistem Kendali Robot Mobil Sederhana Pada Smartphone Android Berbasis Teknologi Bluetooth". Kendari: Universitas Halu Oleo.

[6] Hendra Agusvianto. 2017. "Sistem Informasi Inventori Gudang Untuk Mengontrol Persediaan Barang Pada Gudang Studi": JIEET

[7] Emilia. 2017. "Analisis Sistem": Universitas Dehasen Bengkul

[8] Nurcahyo, Sidik 2012. "Aplikasi dan Teknik Pemrograman Mikrokontroler AVR Atmel"Yogyakarta: Andi

[9] Andi,Sulistia.2016. "Arduino Uno sebagai Sistem Kendali Dan Monitoring Pengaturan Air pada Tanaman Produksi”, Kudus: Universitas Muria

[10] Harry,Yuliansyah.2016." Uji Kinerja Pengiriman Data Secara Wirelles Menggunakan Modul ESP8266 Berbasis Rest Architecture".Sumatra:Graha Ilmu

[11] Amir,Fattah.2014."Robot Line Follower PID Sebagai Media Pembelajaran Aplikasi Mikrokontroler". Yogyakarta:Andi Offset

[12] Fina,Supergina.2014."Perancangan Robot Pencapit Untuk Penyortir Barang berdasarkan Warna LED RGB dengan Display LCD Berbasis Arduino Uno",Jakarta:Alfabeta

[13] Ginon.Pratidhina.2012," Prototipe Robot Line Follower untuk Tuna Netra Berbasis Mikrokontroler AVR-Atmega328 Dengan Board Modul Arduino Unu R2",Yogyakarta: Andi Offset

[14] Setyawan Budi.2016.’'Robot Line Follower Menggunakan Kendali Jarak Jauh Berbasis Android", Surabaya:Pustaka Baru Press

[15] Ridwan Fajar.2016.” Pengertian Pengertian UML Dan Jenis-Jenisnya Serta Contoh Diagramnya", Jakarta: Pengertianku.net 